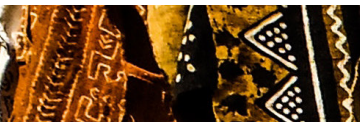

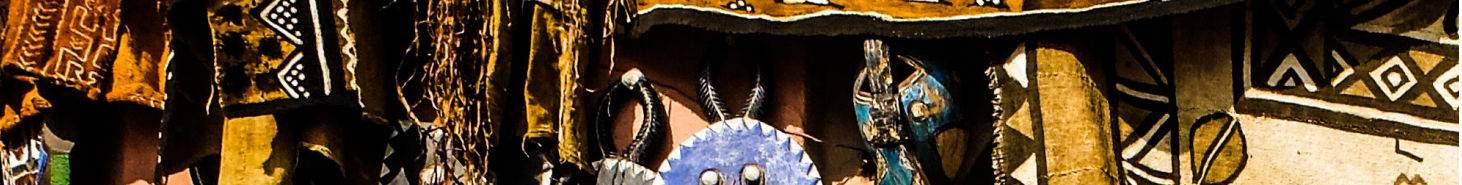

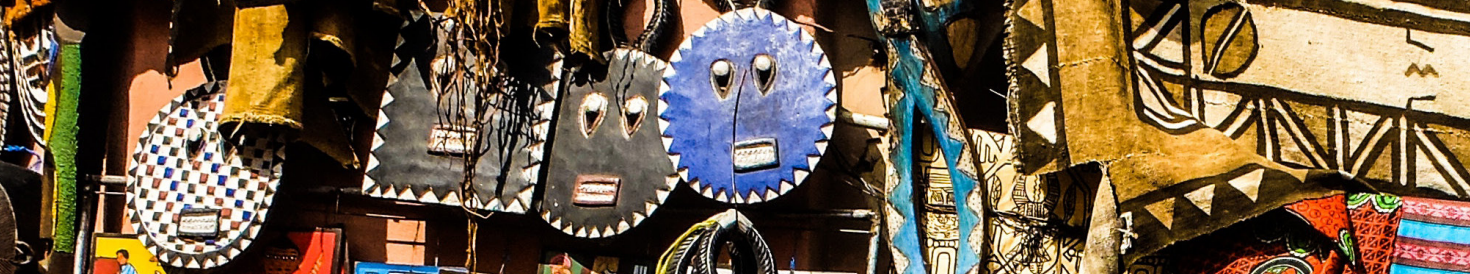

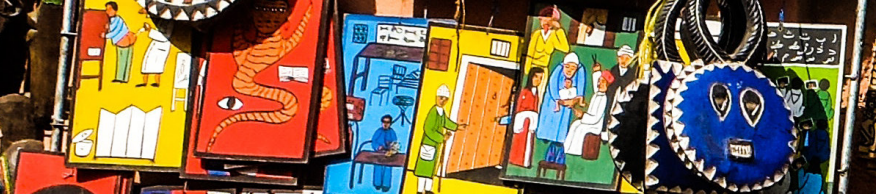

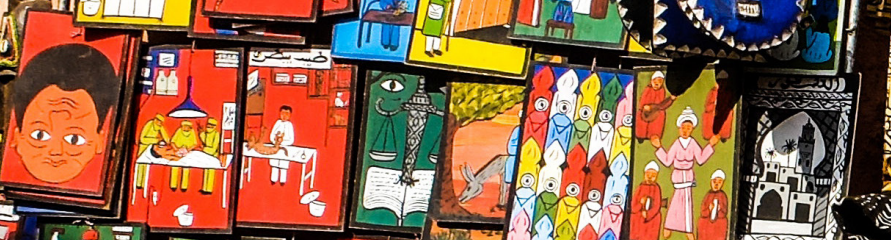

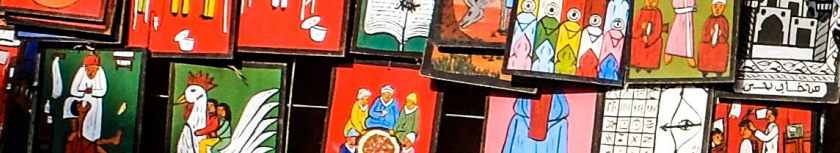
$\underbrace{1}_{-1}$ $\pi)^{2}=0$ (a)
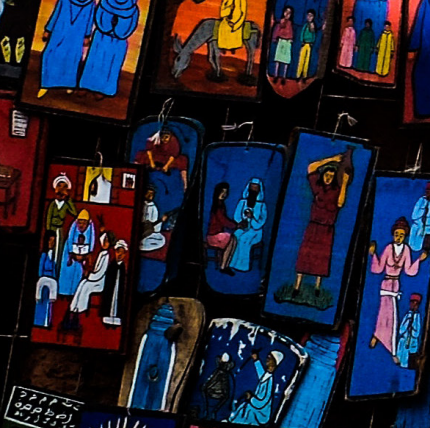

1. (4)

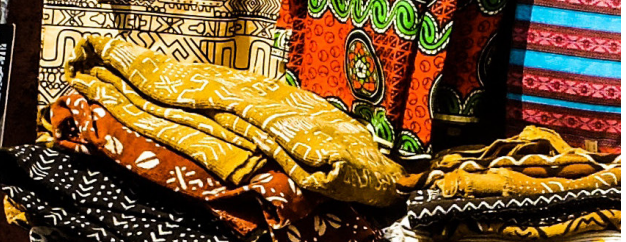

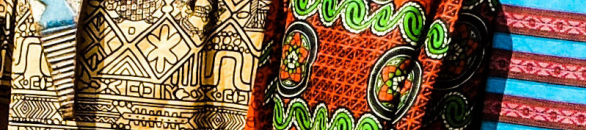
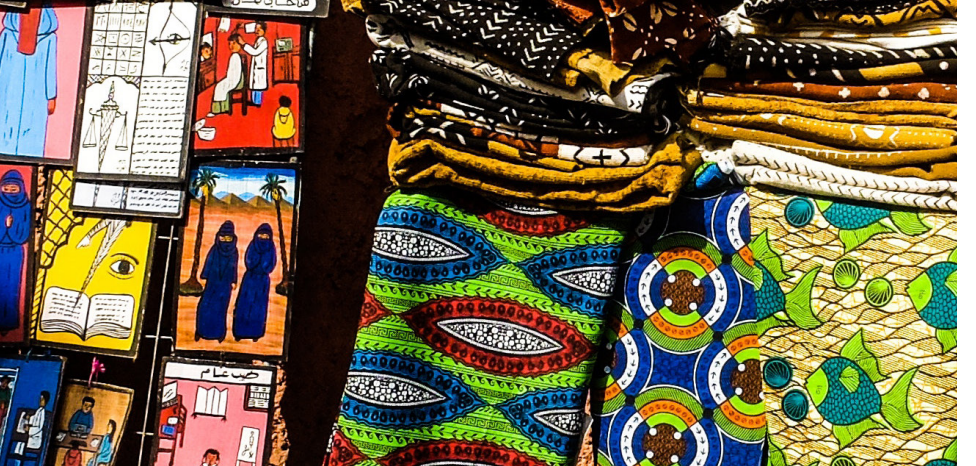

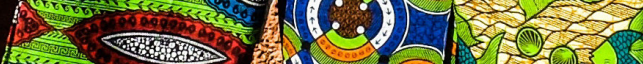
(4)

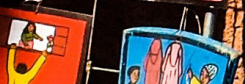
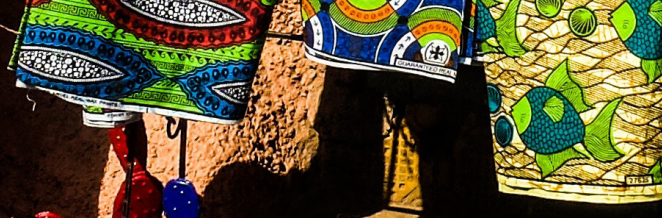
10.4.

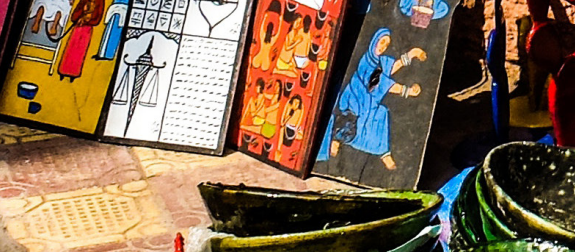

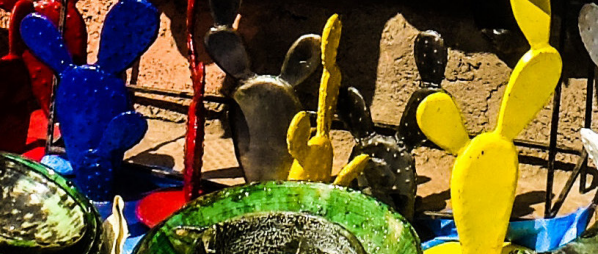

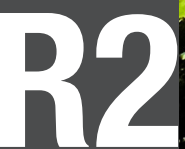

Artigo recebido em: 28/06/2017 Artigo aprovado em: 14/09/2017 DOl 10.5380/2238-0701.2017n14p409-418
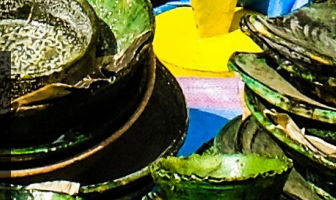
nas No: 
Resenha. Identidades multiculturais. 


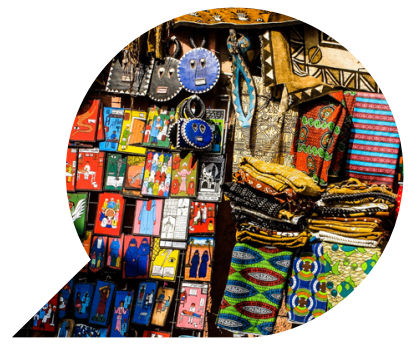

\title{
Bauman e as identidades multiculturais fluídas
}

\author{
Bauman and fluid multicultural identities
}

Bauman y las identidades multiculturales fluidas

\section{PATRICIA BIEGING*}

Resenha: BAUMAN, Zygmunt. Identidade: entrevista a Benedetto Vecchi. Tradução de Carlos Alberto Medeiros. Rio de Janeiro: Jorge Zahar Ed., 2005, 112p.

O livro Identidade é resultado de uma entrevista com o sociólogo polonês Zygmunt Bauman concedida ao jornalista italiano Benedetto Vecchi. Aborda questões relacionadas à construção da identidade como um importante conceito para o entendimento das atuais transformações da vida social. A metodologia presente na entrevista foge dos padrões tradicionais, face a face. Todas as questões e respostas foram feitas através de e-mails, impondo um ritmo fragmentado na troca de informações, possibilitando maior direcionamento das questões em relação ao aprofundamento das respostas.

A estrutura do livro, relativamente pequeno em número de páginas, com pouco mais de cem, mas com conteúdo rico, instigante e por vezes revelador, não apresenta a tradicional divisão por capítulos, a não ser por

* Doutora em Ciências da Comunicação (ECA-USP), Mestre em Educação, na linha Educação e Comunicação (UFSC), especialista em Propaganda e Marketing e graduada em Comunicação Social, com habilitação em Publicidade e Propaganda. E-mail: pbieging@gmail.com 
apresentar uma introdução, o conteúdo propriamente dito e, por fim, algumas notas. Ao contrário, adota uma sequência de perguntas seguidas de respostas, como os vistos em entrevistas publicadas em revistas.

Na primeira parte da entrevista, Bauman situa a questão da identidade como uma espécie de prólogo para as quinze perguntas seguintes. Aponta que as pessoas, ao buscarem sua identidade, se veem diante de uma tarefa intimidadora, que não se dá no tempo real, mas sim na sua infinitude. As identidades estão relacionadas com as comunidades em que estão inseridas, só surgindo da exposição das mesmas. Além disso, são negociáveis, tendo como base as decisões que o indivíduo toma. Nesse contexto, a que o autor chama de época líquido-moderna, situa-se a fragmentação mal coordenada do mundo, enquanto a existência dos indivíduos está dividida entre episódios frágeis e conectados. É neste ponto em que o autor explica que é por isso que as pessoas passam por muitas identidades, sendo expostas a várias comunidades no decorrer da vida.

$\mathrm{Na}$ resposta à primeira questão, Bauman explica que a identidade é sempre algo evasivo, e que nessa condição deve ser considerada um propósito e não algo predefinido. A identidade não é uma descoberta, mas é revelada como algo a ser inventado. Pensar sobre identidade nacional é algo recente e surgiu de uma crise de pertencimento e de um esforço para transpor as questões do que "eu devo ser" com o que "eu sou" na tentativa de recriar, para um indivíduo, uma realidade que seja semelhante a sua ideia.

O autor cita como exemplo o caso Polônia pouco antes da segunda guerra mundial, apontando que naquele contexto o Estado e a $\mathrm{Na}$ ção eram ordens que precisavam uma da outra. Assim, uma Nação sem Estado estaria fadada a uma existência precária. Já o Estado era o que concretizava o futuro de uma Nação com um destino compartilhado. A única característica reconhecida pelas autoridades nos documentos de identidades era o pertencimento do indivíduo a um Estado. Outras identidades, ditas menores, eram forçadas a buscar "endosso-seguidode-proteção" dos órgãos autorizados, confirmando, mesmo que indiretamente, a superioridade da identidade nacional.

$\mathrm{Na}$ questão seguinte, aponta-se que quando a identidade perde suas âncoras sociais torna-se algo cada vez mais importante para os indivíduos. Hoje, os indivíduos buscam se encontrar ou se estabelecer por meios eletrônicos que, por sua vez, são frágeis totalidades virtuais, onde é fácil entrar, mas também é fácil ser abandonado. Essas comunidades 
virtuais não podem dar substâncias à identidade pessoal e, dessa forma, dificultam que o indivíduo chegue a um acordo com seu próprio eu.

Dessa forma, busca-se construir e manter as referências de identidades em movimento com o propósito de se juntarem a grupos também móveis e velozes, na tentativa de manter-se vivo por um curto período. Nesse mundo as identidades antigas, rígidas e inegociáveis, não funcionam. A globalização relega que o Estado não tem mais poder ou desejo de manter uma união sólida com a Nação.

O entrevistador indica na terceira pergunta que a identidade é uma categoria que não tem direito a uma cidadania de pensamento, e que, por meio da esquerda marxista, é apresentada pela primeira vez como problema. Bauman, nesse contexto, sinaliza que por uma visão truncada, reducionista e unidimensional do legado de Marx foi atraída uma geração perplexa e confundida por descontentamentos que não poderiam ser explicados pelas padronizadas teorias de desenvolvimento e progresso. Por isso, é impossível que qualquer modelo baseado em um único fator seja capaz de dar conta da complexidade do mundo, abrangendo a totalidade da experiência humana.

A ideia de um "mundo melhor" foi diminuída diante da defesa de causas relacionadas a grupos e categorias, permanecendo indiferente a privações e desvantagens, não oferecendo uma solução que abrangesse de forma universal aos problemas humanos. Nesse contexto, a produção globalizada criou pessoas rejeitadas, que não são mais necessárias ao funcionamento do ciclo econômico e, portanto, não podem ser acomodadas numa estrutura social da economia. Essa exclusão, mais do que a exploração apontada por Marx, é que aprofunda os casos de desigualdades e o aumento de miséria e de humilhação.

Na questão seguinte, Bauman fala sobre a transformação que levou as identidades a saírem da obscuridade e habitarem os tempos modernos. Para o autor, uma vez livres, os indivíduos se tornariam politicamente interessados e ativos, promovendo efetivamente a justiça, a proteção mútua e a fraternidade. Entretanto, as capacidades do Estado em fazer os indivíduos sentirem-se confiantes e satisfeitos acabou minando suas ambições.

O Estado-Nação perdeu a confiança da população. O significado de cidadania se esvaziou dos antigos conteúdos, enquanto as instituições dirigidas ou endossadas pelo Estado perderam sua credibilidade. Em uma sociedade cada vez mais privatizada, o governo estatal tornou-se uma en- 
tidade menos procurada pelos indivíduos. Isso em virtude de uma experiência de abandono, onde as pessoas suspeitam serem apenas peças de um jogo, que podem ser descartadas quando não derem mais lucro.

$\mathrm{Na}$ quinta questão, utilizando como metáfora o quebra-cabeça, o autor indica que o trabalho de construção de identidade é direcionado para os meios. Entretanto, não se segue uma lógica racional instrumental, como no quebra-cabeça, mas uma racionalidade objetiva, em que uma identidade é construída com todo tipo de materiais disponíveis à mão.

A liberdade que tornou possível aos indivíduos focarem o trabalho de sua vida na construção de identidade, seguida da decomposição do sistema de estados, foi acompanhado por uma confiança em si mesmo e nos outros. Entretanto, essa confiança não possui bases sólidas. A atual situação social está na passagem de uma fase sólida para uma fluída, não conseguindo manter uma forma determinada por muito tempo. Não se pode esperar que as estruturas disponíveis durem por muito tempo. Assim, para a grande maioria dos indivíduos, "atitudes como cuidar da coesão, apegar-se às regras, agir de acordo com os procedimentos e manter-se fiel à lógica da continuidade, em vez de flutuar na onda das oportunidades mutáveis e de curta duração, não constituem opções promissoras" (BAUMAN, 2005, p. 60).

Questionado sobre o ressurgimento do nacionalismo, Bauman explica que esse termo é equivocado, o que se observa é uma nova safra de reivindicações para a autonomia ou independência, e as razões para isso apontam principalmente para uma erosão da soberania nacional. Num estado de crise social, as pessoas culpam a sociedade como um todo, ou outras pessoas por motivos facilmente identificáveis. O Estado não tem mais poder suficiente para proteger seu território e seus habitantes.

A identidade nacional é puramente política. Resta ao indivíduo escolher entre comunidades baseadas na associação de pessoas e opiniões semelhantes, já que a identidade é dada ao nascer e se impõem sobre o indivíduo. Nesse sentido, para os mais inseguros as comunidades são vistas como um paraíso, um sonho tentador, enquanto que para os que lutam se assemelha a uma prisão, um pesadelo.

$\mathrm{Na}$ sétima e oitava questões, Bauman é perguntado sobre a instabilidade das relações amorosas e religiosas vistas na atualidade. Nesse sentido, aponta que a maioria das pessoas tem uma opinião ambígua sobre viver livre de vínculos, com relacionamentos sem compromisso, e ainda, sobre a insegurança de que tipos de relacionamento desejam. 
Amar significa comprometer a própria liberdade. Busca-se o amor na tentativa de encontrar auxílio, confiança e segurança. Entretanto, o compromisso estabelecido ao amar gera seus próprios conflitos e suas próprias incertezas e inseguranças. Dessa forma, tende-se a reduzir os relacionamentos amorosos ao modo consumista, em que a satisfação deve ser instantânea. O valor do amor é única e simplesmente sua capacidade de proporcionar satisfação. Procura-se o relacionamento através de redes de relacionamento, onde é fácil conectar-se ou desconectar-se. O namoro na internet é preferível aos bares, pois se algo der errado, basta apertar o botão delete.

Quanto a relação do homem com o sagrado, o autor recorre a $\mathrm{Ba}$ khtin ao citar o medo cósmico. $\mathrm{O}$ indivíduo, diante da imensurável grandeza e intensidade da natureza, sente-se incapaz e a mercê desses fenômenos. Além disso, o desamparo quanto a uma vida breve e mortal, leva o homem a se agarrar ao sagrado como forma de transcender os poderes da compreensão, comunicação e ação. Percebe-se isso em todas as religiões, onde um Deus é moldado a partir da emoção e do medo da vulnerabilidade e das incertezas. Entretanto, a mente moderna tornou Deus irrelevante para os assuntos humanos. Assim, a preocupação com a eternidade foi substituída pelo agora. Com isso, tudo que não seja a sobrevivência do indivíduo parece ser um mau investimento. As pessoas são treinadas para deixarem de se preocupar com coisas que, aparentemente, estão além do seu controle, concentrando sua atenção e energia em tarefas dirigidas ao consumo.

$\mathrm{Na}$ nona questão, o autor aponta que a identidade é uma ideia ambígua. É um conceito altamente contestável. Os diferentes significados associados ao uso do termo contribuem para minar as bases do pensamento universal. A identidade moderna está mais fraca do que outras, em outros tempos. Ela necessita de "instrumentos coercivos, que dão coragem ao medroso, determinação ao hesitante e solidez às realizações das missões proselitistas" (BAUMAN, 2005, p. 86).

Na pergunta seguinte, levanta-se a questão de países como os Estados Unidos que se posicionam como uma nação que tenta institucionalizar a presença simultânea de identidades coletivas. Nesse contexto, o autor aponta que um grande número de imigrantes escolheu o país com a expectativa de manter, desenvolver e praticar, de forma livre, as distinções religiosas ou étnicas que estavam ameaçadas em seu país de origem. Nos Estados Unidos, na Austrália ou no Canadá, a única coisa exigida dos re- 
cém-chegados era que justificassem fidelidade às Leis do país.

Através do exemplo norte-americano, nota-se que a reação aos problemas de identidade não se mostrou uma bênção absoluta. O Estado politicamente neutro e indiferente à indústria doméstica da identidade criou poucos valores capazes de manter a sociedade unida. $\mathrm{O}$ American way of life, a que os políticos norte-americanos constantemente se referem, se condensa na ausência de qualquer modo de vida reconhecido e universalmente praticado.

Na décima primeira pergunta, o jornalista enfatiza a crítica de intelectuais e filósofos feministas ao conceito de identidade. $\mathrm{O}$ autor cita que nada na condição humana é dado de uma vez por todas ou imposto sem direito de apelo ou reforma. A liberdade de alterar qualquer aspecto e aparência da identidade individual é algo que a maioria das pessoas considera prontamente acessível ou, pelo menos, vê como uma proposta perspectiva realista para o futuro próximo.

A construção da identidade assumiu a forma de uma experimentação sem fim. Assume-se uma identidade num momento, enquanto muitas outras são oferecidas. O equipamento sexual do corpo, por exemplo, é um desses recursos na construção de identidade e, como qualquer outro, pode ser usado para todo tipo de propósito e colocado a serviço de uma ampla gama de objetivos.

Na questão seguinte, o autor presume que o fundamentalismo religioso contemporâneo assume uma lacuna deixada pelo Estado. Certas variedades de igrejas fundamentalistas são particularmente atraentes para a parcela destituída e empobrecida da população, aqueles que são privados da dignidade humana e humilhados. Para essas pessoas, as congregações fundamentalistas fornecem um abrigo tentador e agradável que não pode ser encontrado em outros lugares.

$\mathrm{Na}$ décima terceira questão, o jornalista aborda o crescimento de um tipo diferente de movimento social que é contra a globalização neoliberal. A identidade pode ser um caminho para a emancipação, mas também uma forma de opressão. O autor cita que a globalização atingiu um ponto em que não há mais volta. Todos dependem uns dos outros. Pela primeira vez na história da humanidade o auto-interesse e os princípios éticos de respeito e atenção mútuos de todos os seres humanos apontam para a mesma direção e exigindo a mesma estratégia.

Questionado sobre a utilização da internet como instrumento para criar identidades, Bauman explica que num mundo fluído, é arriscado 
para um indivíduo se comprometer com uma única identidade por toda a vida. As identidades são para serem usadas e exibidas. Como toda a sociedade vive hoje por um viés de mercado, todos nesse contexto são ao mesmo tempo clientes e consumidores, e até mesmo as relações humanas são abordadas pelo uso e consumo.

As duas últimas questões abordam os novos meios de comunicação, que para o autor gera uma era multicultural. Esta reflete a experiência da vida de uma nova elite global, a qual sempre viaja, encontra outros membros da mesma elite global que falam a mesma língua e se preocupa com as mesmas coisas. É uma declaração de intenções, onde se recusa julgar e assumir uma posição em relação a estilos de vida ou valores preferidos. A mídia, por outro lado, fornece a matéria bruta que seus leitores e espectadores possam enfrentar a ambivalência de sua posição social.

A disposição das informações no livro impõe um ritmo dinâmico na leitura em que cada questão e citação apresentadas induzem o leitor a uma reflexão crítica sobre as atuais condições cultural e social nas quais vivemos. Bauman e Vecchi revelam uma realidade que fingimos não ver. Através de sua discussão, mostram que a modernidade criou indivíduos frágeis e inseguros, que se escondem atrás de todas as facilidades tecnológicas e mercadológicas, vivendo de forma rápida e superficial, focados no momento e não pensando em construir algo relevante para suas vidas. Todos os valores são relegados a uma lógica de mercado, de uso e desuso. Nossas várias identidades, fragmentadas, são utilizadas como máscaras para esconder nosso verdadeiro rosto. Neste ponto, o livro Identidade mostra-se como uma obra relevante para a construção de uma visão crítica de nossa postura e lugar no mundo e, quem sabe, ser o primeiro passo na busca da resposta da pergunta que embasou toda a obra, "quem eu sou?" ou "quem nós somos?".

São questões importantes para a própria construção pessoal e crítica diante das pressões e obrigações da vida moderna. É imprescindível para pessoas que trabalham e abordam atividades relacionadas a questões humanas e sociais, mas também para aqueles que de certa forma querem entender mais sobre si e sua posição social no momento histórico em que vivemos.

O autor do livro, o polonês Zygmunt Bauman, é um sociólogo que iniciou carreira na Universidade de Varsóvia. Em 1968, teve várias obras censuradas e foi proibido de lecionar. Em 1971, chegou a Grã-Bretanha, onde se naturalizou. Por vinte anos foi professor titular de sociologia da 
Universidade de Leeds. Atualmente, é professor emérito de Sociologia das Universidades de Leeds e Varsóvia. O reconhecimento de seus estudos se fez presente quando em 1989 recebeu o prêmio Amalfi pelo livro Modernidade e Holocausto e, em 1998, o prêmio Adorno pelo conjunto de sua obra. Entre outros títulos publicados estão: Amor líquido; Comunidade; Em busca da política; Europa; Globalização: as consequências humanas; O mal-estar da pós-modernidade; Medo líquido; Modernidade e ambivalência; Modernidade e holocausto; Modernidade líquida; Tempos líquidos; Vida Líquida; e Vidas desperdiçadas. 